\title{
Failure Analysis of Flood Collapse of the Tex Wash Bridge
}

\author{
Maryam Tabbakhha, Abolhassan Astaneh-Asl, Daniel Christian Setioso \\ University of California at Berkeley \\ Berkeley, California, USA \\ astaneh@berkeley.edu
}

\begin{abstract}
Located east of City of Palm Springs, the Tex-Wash Bridge is a bridge over the Tex-Wash dry river on Interstate Highway 10. On July 19, 2015, one of the three spans of the Tex-Wash Bridge collapsed due to flooding resulting from heavy rain. This paper summarizes the failure analysis to understand the cause of this collapse, and to learn engineering lessons from this collapse. Using the "As-Built" drawings of the bridge, a nonlinear FE model of the bridge was created in ANSYS. The model then was subjected to simulated flood waters until the bridge collapsed. By studying the results of FE analysis it was concluded that the collapse occurred due to combination of five factors: (1) the bridge had a length of about half of the width of the flood path, creating a bottle-neck on the path of the flood, (2) flood waters before reaching the bridge made an " $\mathrm{S}$ " curve turning right and then left before going under the bridge, which resulted in washing the soil under the east abutment, (3) the east abutment was supported on fill soil without piles, therefore when the supporting soil under the abutment washed away, it could not be supported and collapsed, (4) the wing walls in the abutment were perpendicular to the flood waters, resulting in flood waters pushing the abutment and collapsing it, (5) when the abutment lost its supporting fill-soil and was pushed by flood and collapsed, the deck slab of the roadway supported on it also collapsed.
\end{abstract}

Keywords: Bridge Engineering, Structural Engineering, Failure Analysis, ANSYS, Flood Protection, Scour, Concrete Bridge.

\section{Introduction}

Bridges are one of the most important components of transportation systems. Their vulnerability against natural disaster, like earthquakes and floods, can cause fatal catastrophes and often results in significant economic losses and disruption of major transportation links. Overturning the water on the deck, erosion of the soil under the piers and abutment footings, and impact of floating debris on the deck, guard rails, piles and abutments are the main reasons that floods cause bridge collapses. The 1993 flood on the upper Mississippi River and Midwest, 1995 California flood, and 1997 Northern California floods are examples with \$20 billion, \$1.8 million and \$35 million total economic loss respectively that shows the importance of carefully investigating the effect of floods on bridges [2], learning lessons from these failures and developing concepts and technologies that can prevent such failures in the future as well as loss of life. In the most recent flood event in southern California, a span of the Tex Wash Bridge collapsed due to floodwaters from the monsoonal weather on July 19, 2015. This bridge is located east of City of Palm Springs on Highway 10 that links Los Angeles to Phoenix. The bridge carries the two east bound lanes of traffic on the Interstate Highway 10 with more than 11200 vehicles a day crossing the bridge of which $40 \%$ are trucks [1]. The 3-span bridge has a total length of $27.42 \mathrm{~m}$ and a width of $12.5 \mathrm{~m}$.

Due to the complexity of site geometry, behavior of fluid and interaction between fluid and structure, using a computational tool presents certain challenges. In the present study, the Tex Wash bridge is modelled using a one-way coupling system and the effect of flood on the surrounding soil and bridges are investigated in detail using numerical methods. In this type of modelling a converged solution is obtained from one field and then used as a boundary condition or external force in the other field. The soil and structure are modelled in ANSYS MECHANICAL while the flood is modelled in ANSYS Fluent. These two systems are coupled to investigate the interaction between flood and bridge. 


\section{Flood Collapse of the Bridge}

According to the U.S. National Weather Service of National Atmospheric and [2] "The moisture surging north from the remnants of Hurricane Dolores combined with the old circulation centre spinning off the southern California coast, Fig. 1 (left) created the conditions ripe for numerous thunderstorms and flooding throughout southeast California on July $19^{\text {th }}$, 2015. Thunderstorms developed quickly over southeast California early in the day, and persisted into the evening hours. The very moist environment allowed for these storms to become efficient rain producers." Fig. 1(right) shows a shot of radar loop during the day from ref [2] with location of the bridge shown on the radar loop shot. The storm, moving slowly, impacted the same areas with prolonged heavy rainfall, especially along Interstate Highway 10 where the bridge was located. On the late hours of afternoon of July 19, 2015, the combination of heavy rainfall rates and prolonged residence time over the area where the Tex Wash Bridge is located resulted in extensive flash flooding. Fig. 2 from Ref [2] shows the rainfall over a 24-hour period on July $19^{\text {th }} 2016$. During the flood, $17 \mathrm{~cm}$ rain fell over a span of only 6 hours, with rain falling at a rate of $9 \mathrm{~cm}$ per hour during a peak 30-minute period. This caused large amounts of flood water to rushdown the Tex wash (i.e. dry riverbed) and try to pass under the Tex Wash Bridge. According to meteorologist Valerie Meyers [1], the flood could be considered to have a 1000 year return period. She added that "Just because we are saying this is a 1,000-year storm doesn't mean it's only going to happen once in one thousand years. We are just describing the rarity of the event. It could happen next week. It could happen 5 miles down the road. It could happen tomorrow."
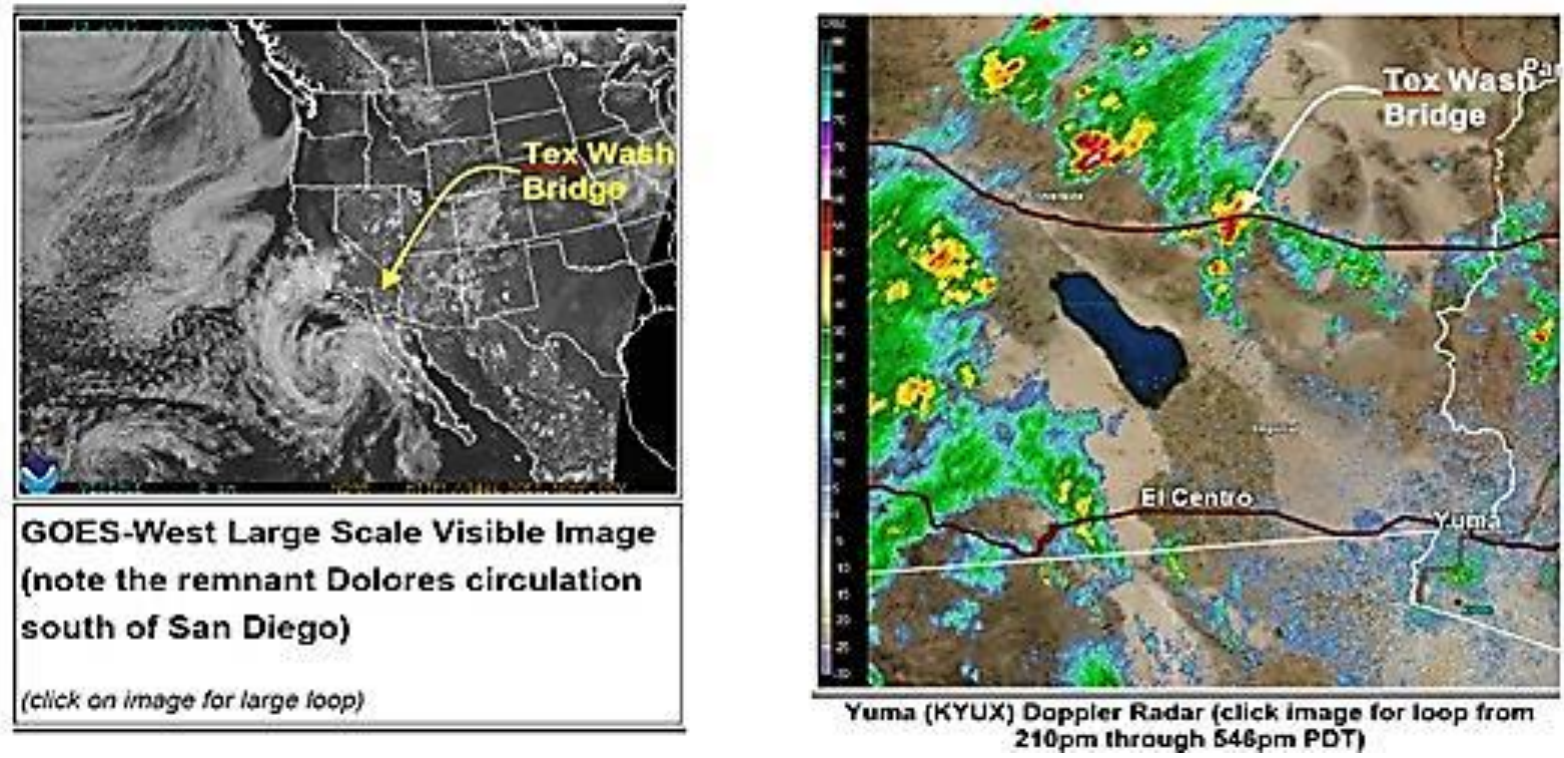

Fig. 1: Areal Views of the Tex Wash Bridge prior to collapse and flow of flood waters.

Fig. 3 shows areal views of the Tex Wash Bridge and direction of flash floods collected on its south side and rushed to pass under the bridge. As can be seen in Fig. 3, the channel that is directing the flood waters to the bridge is not straight. When the flood water flows north and arrives at the flat lands of Palm Desert, a relatively wide delta is formed. However, when the Tex Wash Bridge was designed and constructed in the 1960's, the California Department of Transportation (also called Caltrans) narrowed the width of the delta from about 70 meters to only about 30 meters, presumably to save in the costs of construction. As a result, the flood waters, instead of flowing unhindered through the delta and being dispersed into the floor of the valley, ended up forced to make a 90-degree turn to the right and flow about 100 meters' parallel to the Interstate Highway 10 and then make another 90-degree turn, this time to the left and pass under relatively short bridge. This turning of flood path without carefully studying the pressures that will be exerted on the embankment and bridge foundations and piers, was one of the four main design flaws that combined with other three, to be discussed later in this paper caused the collapse of the bridge. 


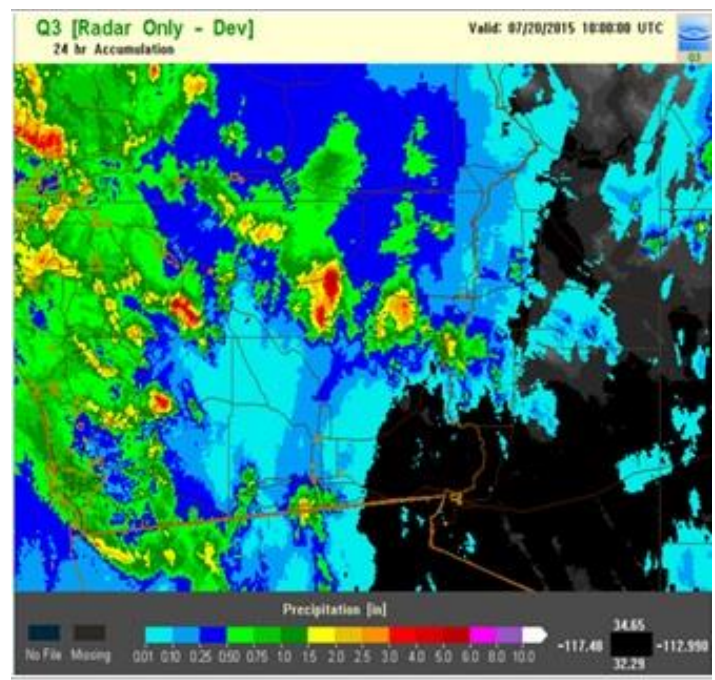

Radar Estimate Rainfall Data (Source NSSL Q3)

Fig. 2: Rainfall estimate over 24 hours.
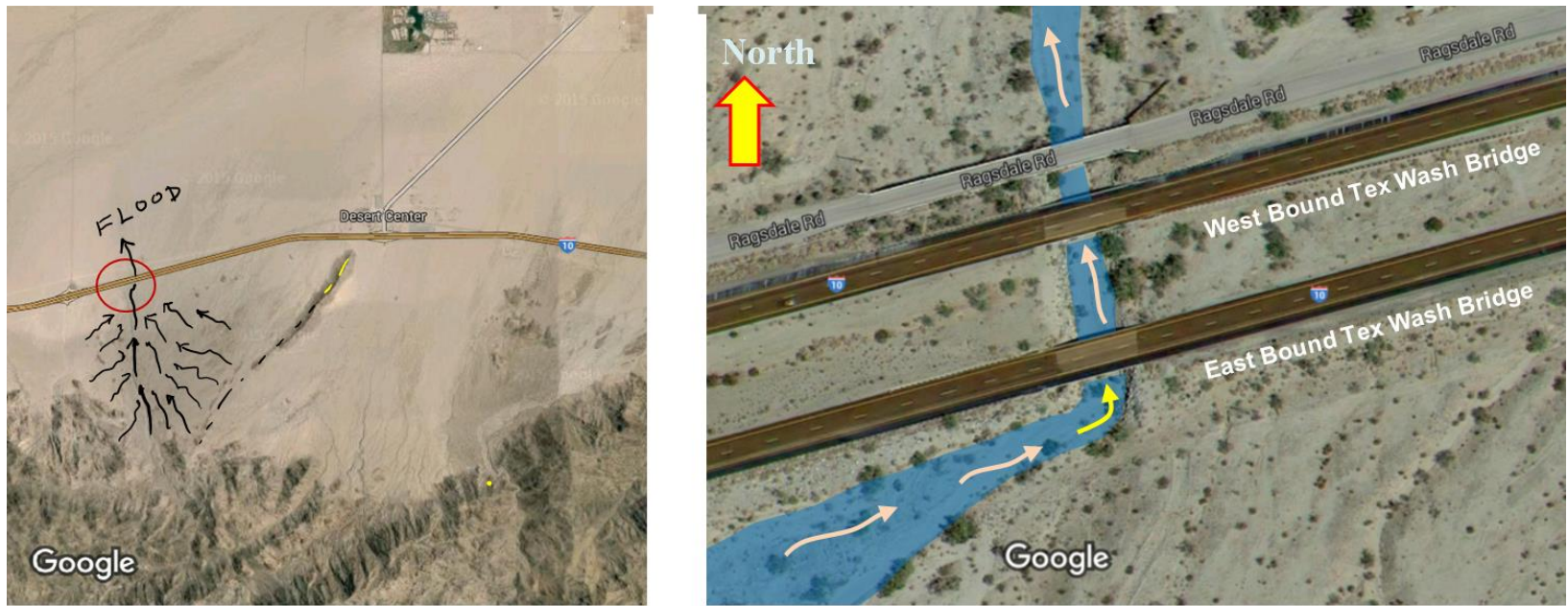

Fig. 3: Areal Views of the Tex Wash Bridge prior to collapse and flow of flood waters.
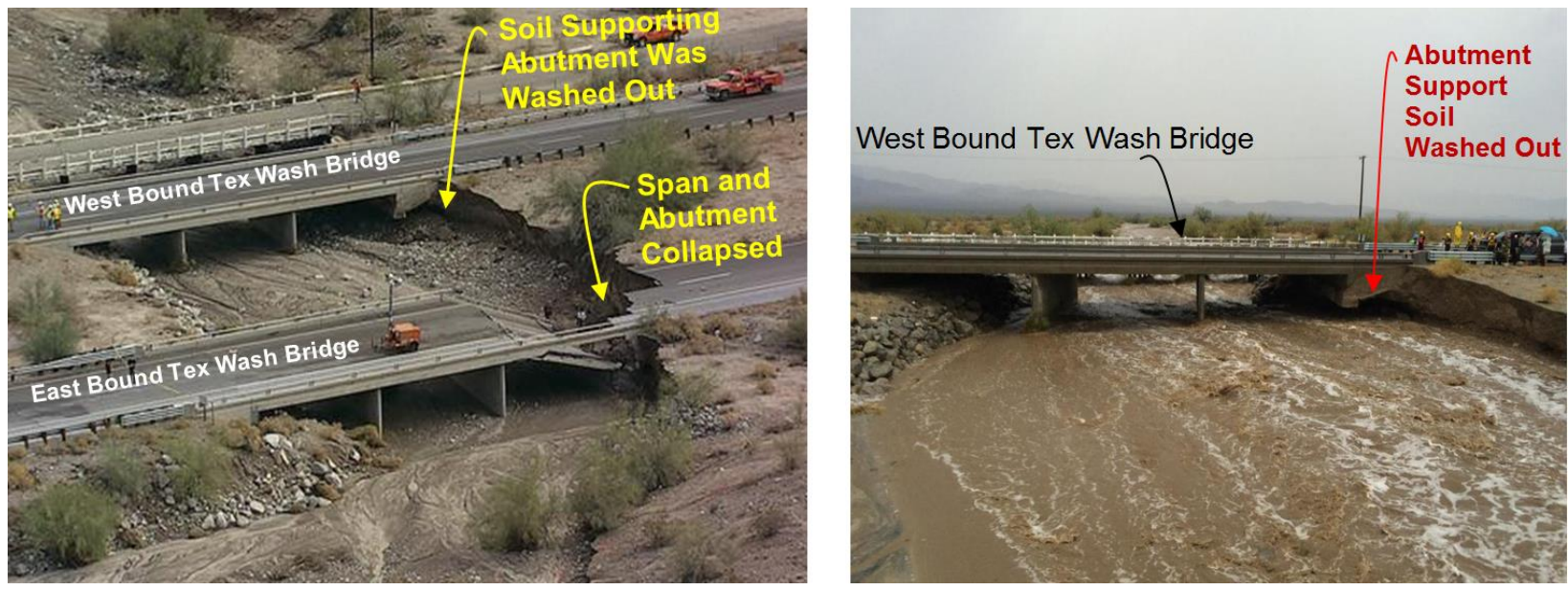

Fig. 4: Eastbound Tex Wash Bridge after Collapse. 


\section{The Structure of the Collapsed Bridge}

Tex Wash Bridge was constructed in 1967 on Interstate Highway 10 connecting Los Angeles to Phoenix in southwestern part of the United States. The Tex Wash Bridge is actually two parallel but separate and almost identical bridges, one carrying the eastbound traffic and the other carrying the west bound traffic. We will primarily focus on the east bound bridge that collapsed due the flood. The west bound bridge was also in the verge of collapse before the flood subsided. As Fig. 5 shows the bridge has a $41.3 \mathrm{~cm}$ thick reinforced concrete deck slab supported on two abutments and two wall piers. The abutments and wall piers are also reinforced concrete. Note that the right side abutment is sitting on infill soil. The flood pressure washed this soil out of under the abutment and left the abutment unsupported resulting in its collapse. Also note that the wall piers were safely supported on very deep foundations.

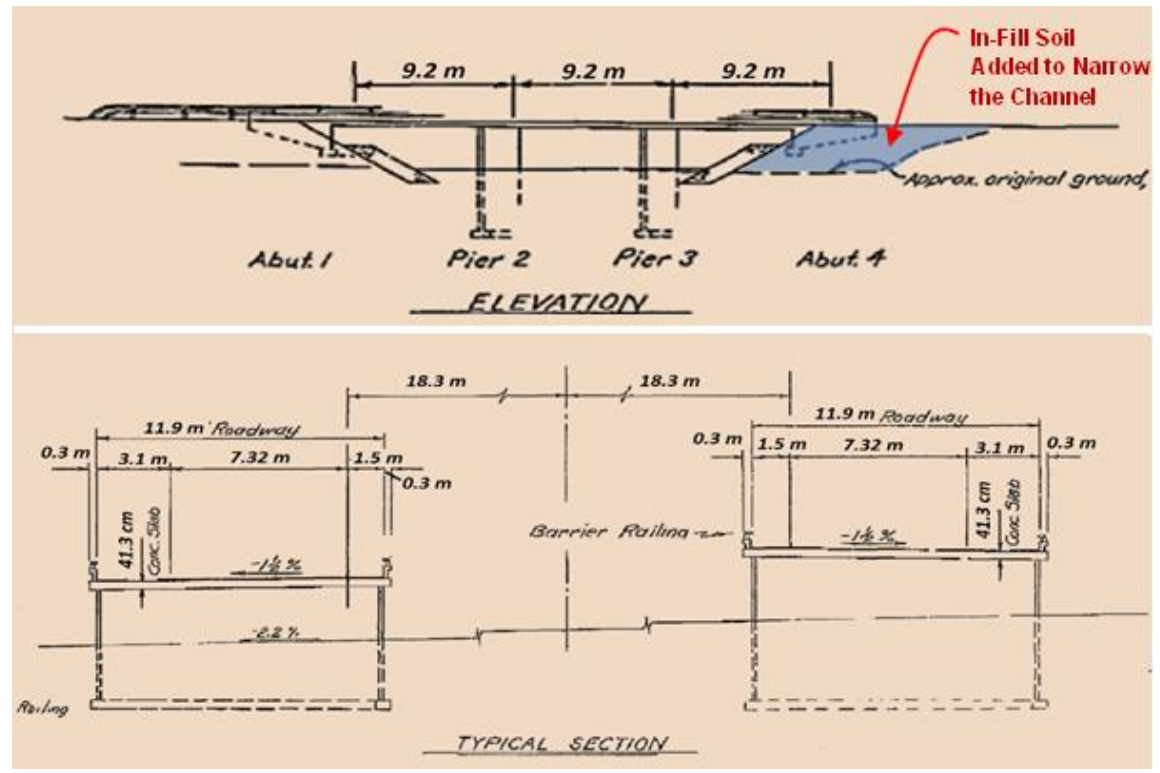

Fig. 5: Structure of the Tex Wash Bridge.

\section{Nonlinear Finite Element Modelling and Analysis}

The interactions between water flood and Tex-Wash Bridge were modelled using ANSYS-Workbench V15.0 by coupling ANSYS-Fluent and ANSYS-Structural software. In this study, a 3-dimensional non-linear model was created to study the behaviour of structural system during the flood with more detail. The one-way coupling method was applied to simulate the fluid-structure interaction (FSI). In this method, the pressure distribution due to the fluid movement is calculated in ANSYS-Fluent, first. Then, the resulting forces at the interface between fluid and structure are imported to the structural model. Finally, the structure is analysed under applied loads until convergence is reached.

\subsection{Modelling Material and Geometry}

We created the geometry of the Tex Wash Bridge site in detail in ANSYS Geometry based on the "As-Built" construction drawings. The wash (i.e. the dry river), the east bond and west bond bridges, and the in-fill soil, which was added during the construction to narrow the width of the wash shown by dash line in Fig. 5, were modelled in ANSYS Geometry. In the next step, the geometry was imported to the ANSYS-Fluent and Structural separately. The structural bodies and fluid body were then suppressed in ANSYS-Fluent and Structural respectively, before the meshing. Fig. 6 shows the modelled geometry of the site in ANSYS Geometry. The length of the dry river before curve and beyond the west bond bridge was selected to minimize the interference of boundary conditions. 


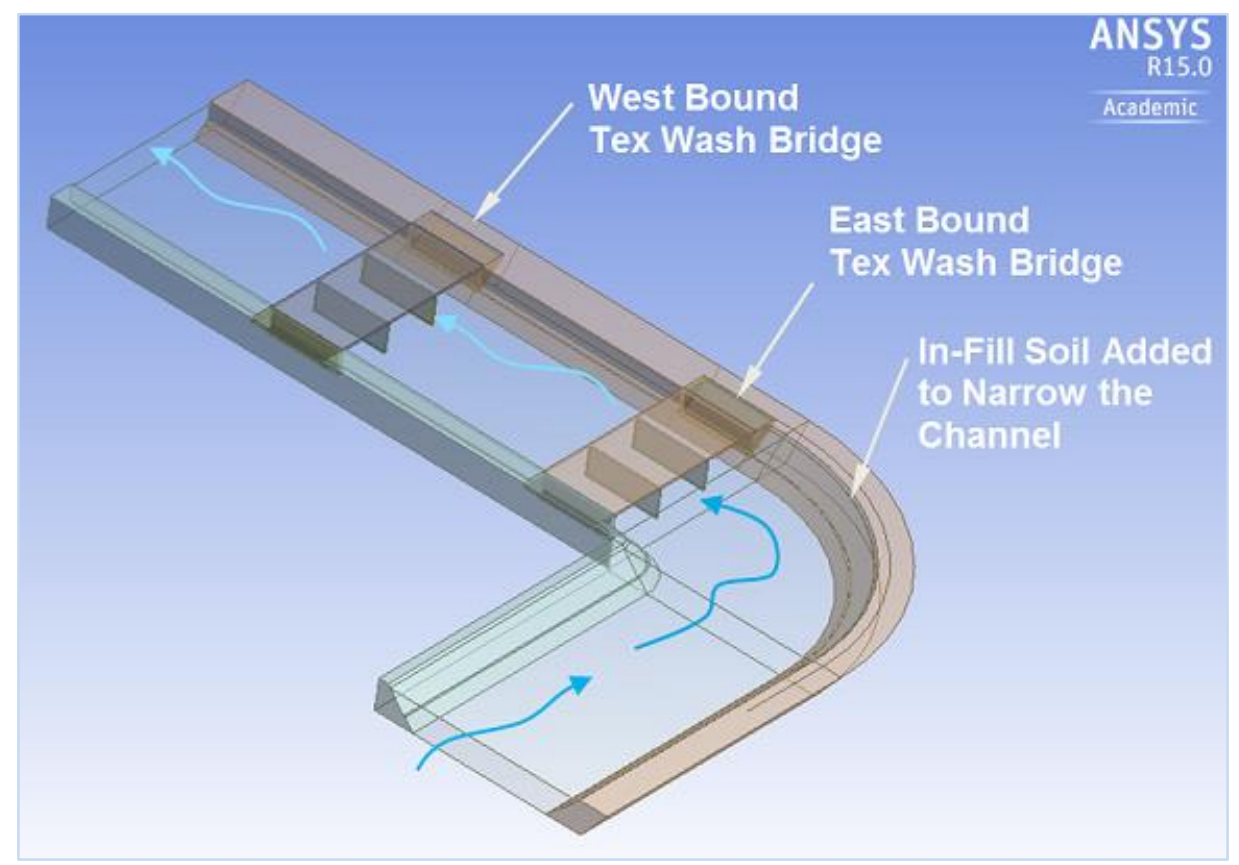

Fig. 6: Geometry of Tex Wash Bridge Site.

The material for the bridges is concrete with modulus of elasticity equal to $20 \mathrm{GPa}$ and strength, established using cylinder compressive specimen according to U.S. ASTM standards as $f_{t u}=3 \mathrm{MPa}$, and $f_{c u}=17 \mathrm{MPa}$ where $f_{t u}$ and $f_{c u}$ are ultimate tensile and compressive strength respectively. Since, detailed modelling of the soil washed away by the flood waters is very complex and out of scope of this research, some assumptions were made to represent this phenomenon in a realistic manner. Hence, a small modulus of elasticity and compressive strength were chosen for the soil material properties to simulate its behaviour under the flood pressure. The assumed modulus of elasticity and compressive strength of soil used in these studies were $0.1 \mathrm{MPa}$ and $5 \mathrm{KPa}$ respectively.

\subsection{Fluent Model for One-Way FSI Analysis}

ANSYS-Fluent structural analysis software was used to calculate the ever-changing direction of the flood waters and the resulting pressure applied by the fluid onto the structural elements and to determine the velocity profile of the flood and it entered the channel and exited after passing under the west bound bridge, see Fig. 6. Then, the obtained pressure was imported to the structural model as input forces. The ANSYS-Fluent software uses the finite volume methods to solve the equation at each node. So, the mesh should be fine enough to obtain accurate results. In this study, an automatic mesh was generated with a fine Relevance Centre and High Smoothing. The minimum and maximum sizes of the mesh were selected as $15 \mathrm{~mm}$ and $1500 \mathrm{~mm}$ respectively. The standard $\mathrm{k}-\varepsilon$ mode was used for the turbulence modelling. The density of water also was increased to $1500 \mathrm{~kg} / \mathrm{m}^{3}$ to consider the weight of particles and mud in the water during the flood. Velocity Inlet and Pressure Outlet was selected as the fluid boundary condition. The velocity of the flood was assumed to be $8 \mathrm{~m} / \mathrm{s}$. This based on analysis of a video of flood movement under the bridge available at ref [3].

The contours of velocity and pressure during the flood are shown in Fig. 7 and Fig. 8 respectively. As shown in Fig. 7, the velocity of the flow within the east bound bridge piers is higher than the other parts. Moreover, as shown in Fig. 8, the level of pressure at the location of river turn is much higher than the other parts and that's where the relatively soft infill soil was located. The unit scales are shown in the left side of each figure. Fig. 9 and Fig. 10 show von Mises stresses in the bridge and displacement of embankment soil respectively. 


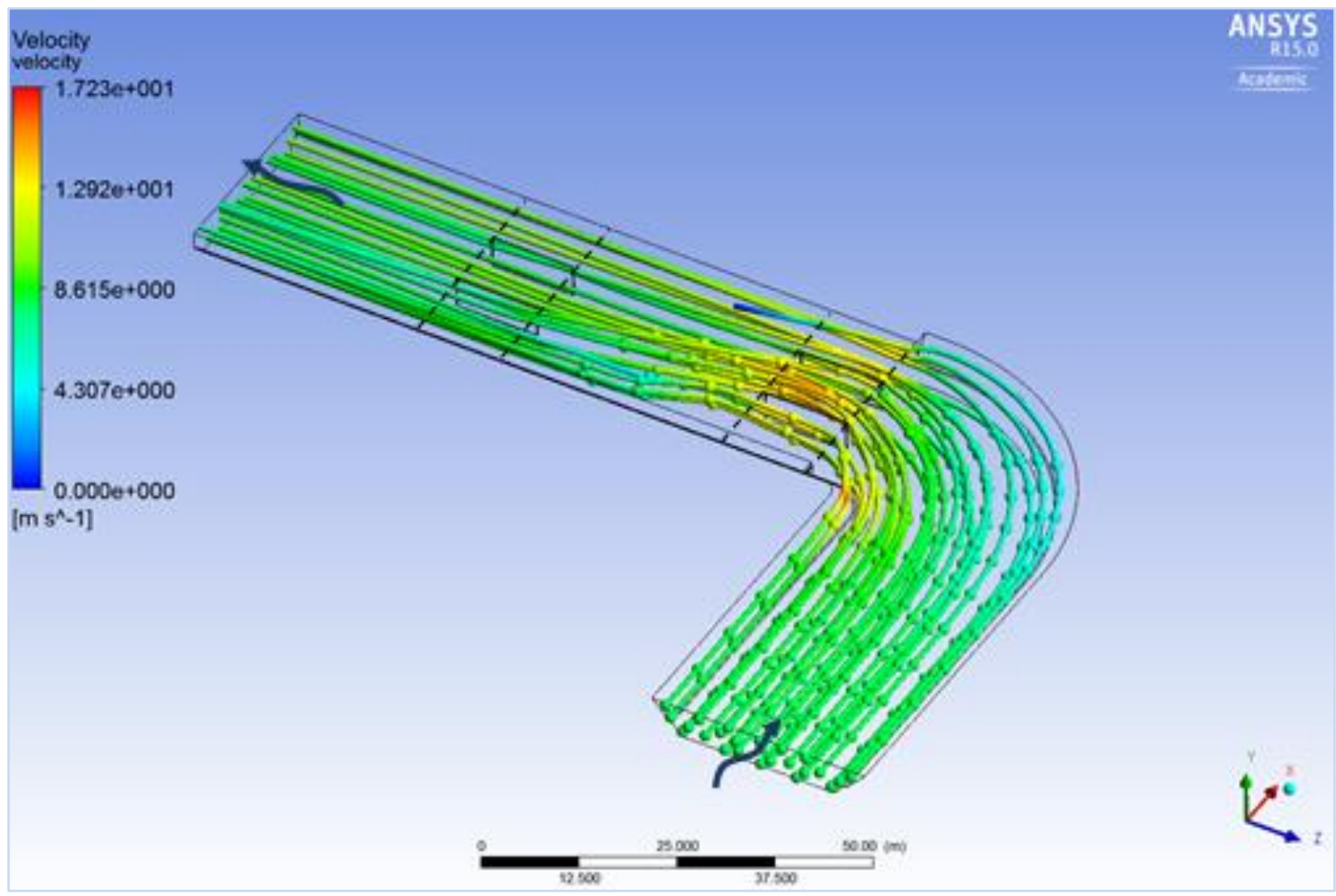

Fig. 7: Velocity Profile of the Fluid Flow.

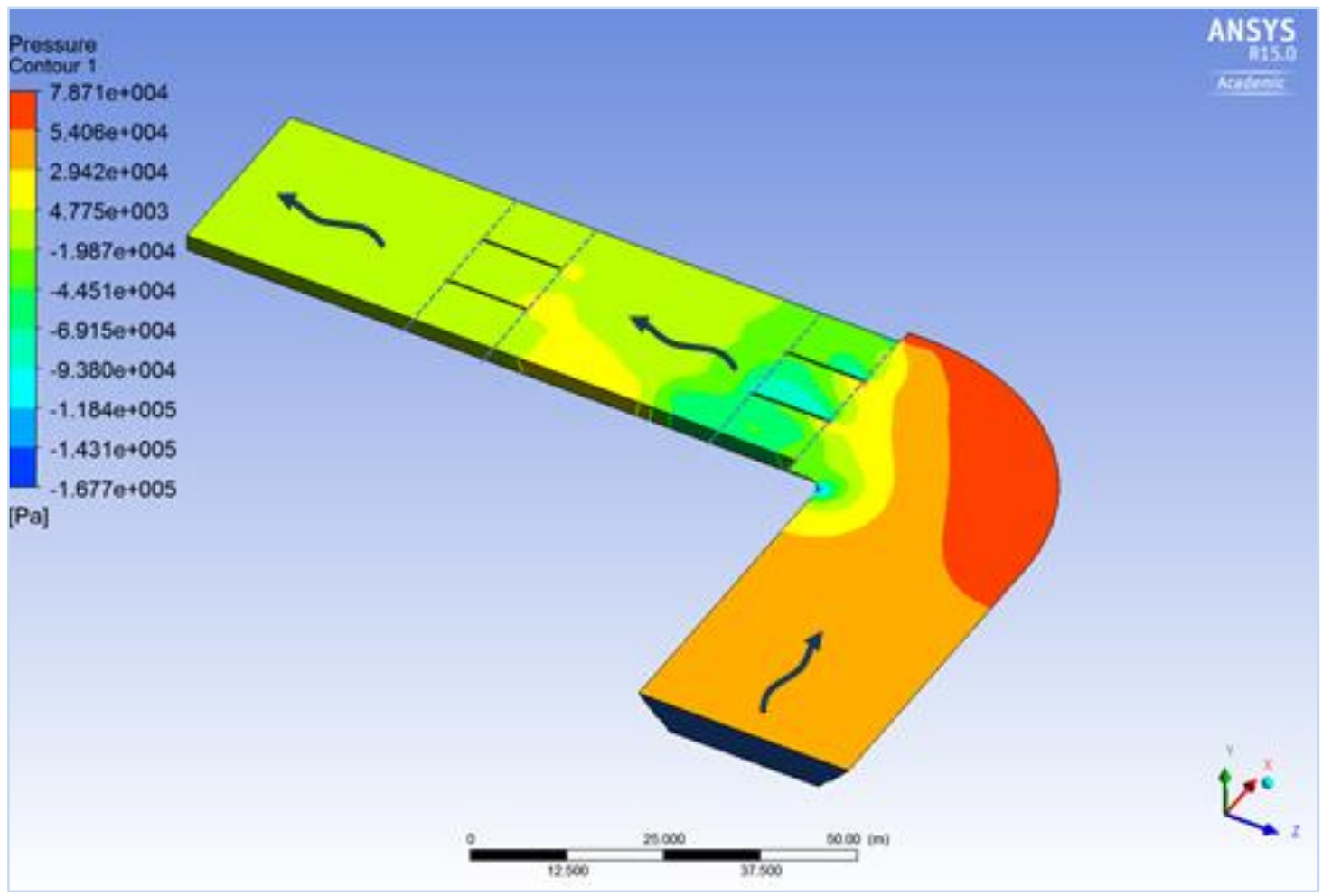

Fig. 8: Pressure Contour of the Fluid Flow. 


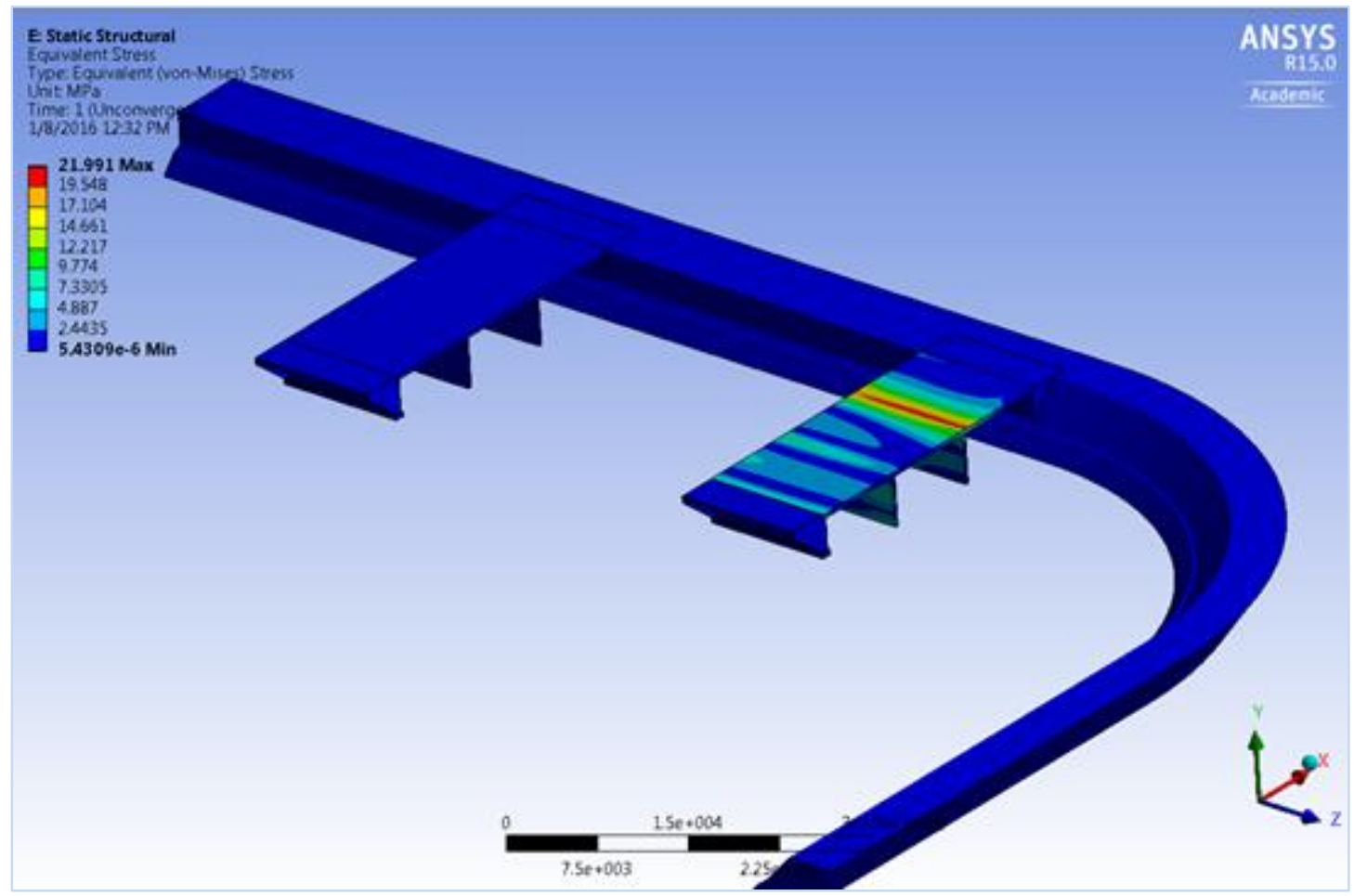

Fig. 9: Von-Mises Stresses of the Bridge Due to the Flood.

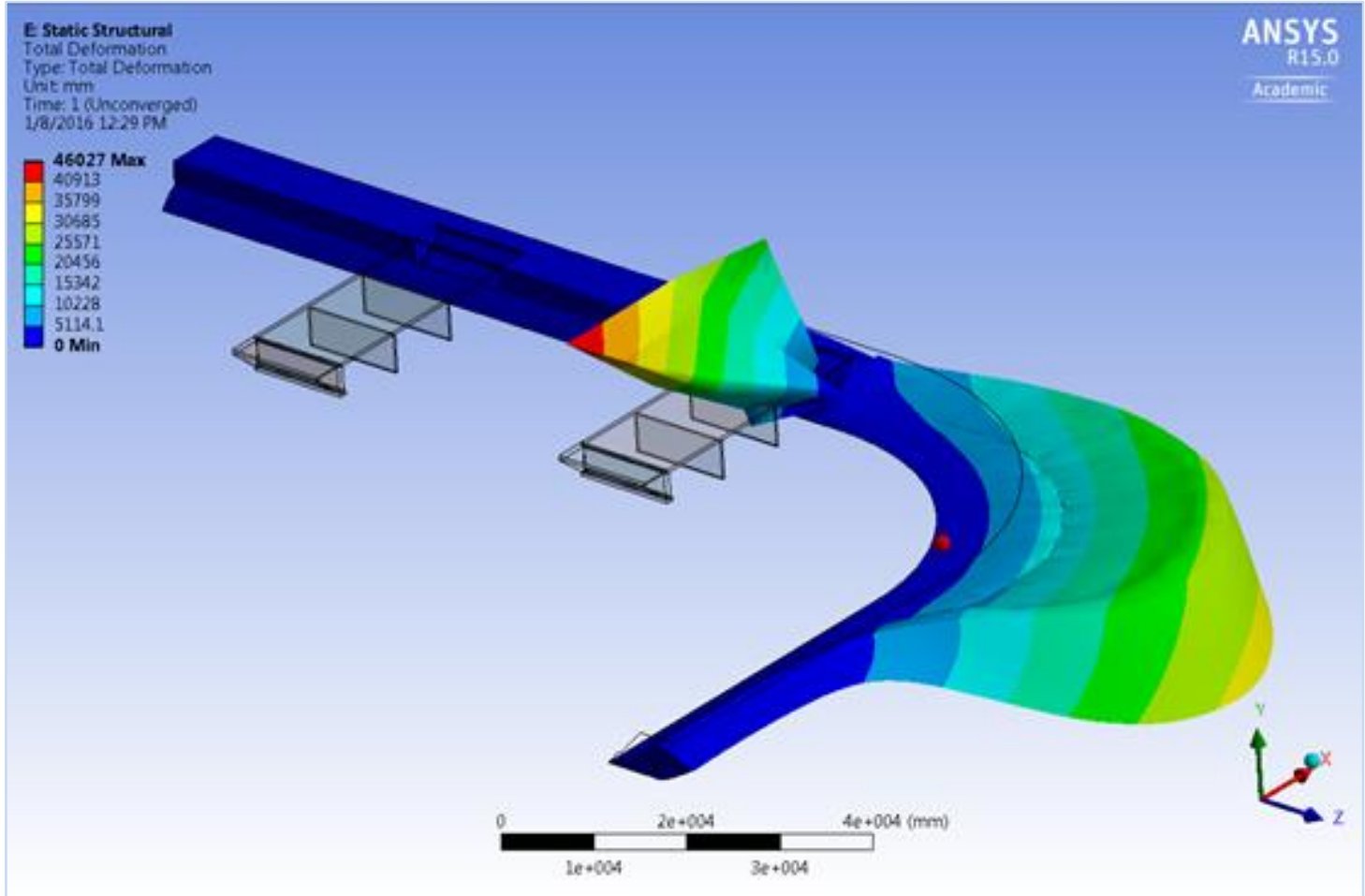

Fig. 10: Displacement of the Soil Due to the Flood. 


\section{Conclusion}

The study of collapse of Tex Wash Bridge indicated that there were four major design flaws that collectively resulted in the collapse of the Tex Wash Bridge. These were:

1. The flood path down the slopes when arrives at the flat valley floor becomes a relatively wide delta. When the bridge was designed this delta was narrowed creating a bottle neck. In addition, due to narrowing of the delta, the flood water is forced to turn right, and then almost immediately turn left to pass under the bridge. The creation of this S-shape path resulted in turbulence in the flood path as well as increased the pressure on the soil supporting the abutment. The high pressure of the flood waters washed away the embankment soil supporting the abutment causing it collapse.

2. The soil supporting the abutment was just infill soil placed in the path of flood to narrow the delta and make the bridge shorter. The abutment instead of supported on piles passing through this relatively soft soil were just directly supported on the infill soil without any pile.

3. The embankments did not have any retaining walls to protect them against scour and being washed away by flood waters.

4. The wing walls of the abutments were perpendicular to the flood water instead of parallel or under a relatively small diagonal angle.

Nonlinear finite element analysis was conducted to investigate the effects of these design flaws on the behaviour of bridge subjected to flood waters. The analysis showed that all of these four design flaws contributed to the collapse. Had there been proper retaining walls, or wing walls almost parallel to the flood path to protect the embankment, and the abutment was supported on the piles instead of relatively soft infill soil, the bridge most likely would have survived the flood without much damage or collapse. Of course the main initiating event was the creation of S-curve on the flood path right before the bridge.

\section{Acknowledgements}

This paper resulted from a project: "Analysis of Failure of the Tex Wash Bridge due to Flood and Lessons Learned" conducted at the University of California Berkeley (2015-2016) with Professor Abolhassan Astaneh-Asl, Ph.D., P.E. as Principal Investigator, Dr. Maryam Tabbakhha as Co-Principal Investigator and Mr. Daniel Christian Setioso, Undergraduate Student Researcher. The authors would like to express their sincere appreciation for the tremendous technical support provided by Dr. Metin Ozen, President, as well as Casey Heydari, and the analysts at the Ozen Engineering Inc. (https://www.ozeninc.com/) on the use of the powerful ANSYS nonlinear structural analysis software packages featured in this project. The authors also would like to acknowledge the input and participation of Xin Qian, doctoral graduate student researcher in this project.

\section{References}

[1] Kelman, B. (2016, January 8). Doomed to fail? Collapsed I-10 Bridge had 4 crucial design flaws, new study says. Investigative Report in the Sun Desert Newspaper, [Online]. Available: http://www.desertsun.com/story/news/2016/01/07/tex-wash-bridge-collapse/78270430/

[2] NOAA. (2015, July 20). Southeast California Flooding - July 19, 2015. National Weather Service [Online]. Available: http://www.wrh.noaa.gov/psr/pns/2015/July/19July/Jul19_flood.php

[3] CBS-This Morning (2015, July 19). Video of Flood under Tex Wash Bridge [Online]. Available: https://www.youtube.com/watch?v=QtChcNeNbEs

[4] A. Astaneh-Asl, M. Tabbakhha and D.C. Setioso. "Analysis of Failure of the Tex Wash Bridge due to Flood and Lessons Learned," Report Number UCB/CEE-Steel-2016/01, Department of Civil and Env. Engineering, Univ. of California, Berkeley, February 2016. 